\title{
Smilidarnis, a new genus with two new species of Membracidae from South America (Homoptera) ${ }^{1}$
}

Gabriel Simões de Andrade 2

\begin{abstract}
Smilidarnis gen. $n$. (type-species: Smilidarnis fasciatus sp. n.) from Aguaytia, Peru and S. concolor sp. n. from Rio de Janeiro, Corcovado, Brazil are described and illustrated.

Smilidarnis gen. n. with two species, S. fasciatus sp. n. from Aguaytia, Peru and $S$. concolor sp. n. from Rio de Janeiro, Corcovado, Brazil are described and illustrated. This new genus is peculiar within the family Membracidae, presenting characters both of Smiliinae and Darninae.
\end{abstract}

Smilidarnis gen. $\mathrm{n}$.

Type-species: Smilidarnis fasciatus sp. n.

Head triangular, more large than long, with smooth surface;superior margin arched; coronal suture apparent only at base; eyes spherical in front view, ovate in lateral view; ocelli nearer to each other than to the eyes, placed below the imaginary line that cross through center of eyes; space between ocelli convex and between ocelli and eyes plain or depressed; supra-antenal lobules excavated, with margins rounded; frontoclypeus sublosangic, with distal half directed forward or downward.

Pronotum wedge shaped, with punctated surface, longitudinally depressed at sides of the median third, ending in a median process that surpasses the level of the $\mathbf{r}-\mathbf{m}$ crossvein of the tegmina and with two lateroapical processes of variable length, giving to the apical portion the shape of a trident; metopidium with the muscular impressions ovate and well apparent; post-ocular lobules with a transverse carina and angulate at level of external angle of eyes; humeral angles well apparent, obtuse in dorsal view; dorsal carina apparent only at distal third.

Tegmina entirely free, with veins $\mathbf{R}, \mathbf{M}$ and $\mathbf{C u}$ fused basally, $\mathbf{R}+\mathbf{M}$ strongly divergent little before middle and $\mathrm{Cu}$ divergent at base, with one $\mathbf{r}$, one $\mathbf{r}$ $\mathbf{m}$ and two $\mathbf{m}$-cu crossveins; five apical and three discoidal cells. Hindwings with one $\mathbf{r}-\mathbf{m}$ and one $\mathbf{m}-\mathbf{c u}$ crosseveins; four apical cells.

1. Contribuição nº 670 do Departamento de Zoologia da Universidade Federal do Paraná. Caixa Postal, 19020 - 81504, Curitiba-PR, Brasil.

2. Pós-graduação em Entomologia, Mestrado-UFPR. Bolsista do CNPq. 
Pro- and mesothoracic legs with tibiae triquetrous, without cucullate femoral or tibial setae; metathoracic legswithout processes on coxa and trochanter, femur without longitudinal row of cucullate setae, tibia triquetrous with three longitudinal rows of cucullate setae, rows II and III double, first tarsomere without cucullate setae on plantar surface, but at least with two cucullate setae apically, second tarsomere with one cucullate setae apically and third tarsomere without cucullate setae.

Abdominal segments III-VII without dorsal pairs of faint fenestrae or elevated middorsal tuberosities.

\section{Smilidarnis fasciatus sp. $\mathrm{n}$.}

(Figs. 1-8)

Type and type-locality. Holotype male with the following label data: "LORETO/Aguaytia, m.400/PERU. Bordón/leg. 21 VI 1974” (printed). The type is deposited in the "Museu de Entomologia Pe. Jesus Santiago Moure", of the "Departamento de Zoologia da Universidade Federal do Paraná, Curitiba, Brasil”.

Measurements (in mm). Head width: 3,56; head length: 1,56; distance between the humeral angles: 4,16 ; distance between the apices of the lateroapical processes: 2,80; pronotal length: 10,00; total length: 11,67.

Description. Holotype male. General color dull-yellow; head with four brown longitudinal bands, two at the eyes and two at the ocelli; pronotum with one brown transversal band located just behind the middle and also six brown longitudinal bands, two lateral arising at the post-ocular lobules, diagonally directed upward and backward till to fuse with the transversal band, and four median in continuation of those from the head, confluent to the space between humeral angles and continuing till to fuse also with the transversal band; distal portion of the median process, of the lateroapical processes and a annular spot on base of the lateroapical processes, black; tegmina and veins yellow-amber; ventral surface of the body and legs, dull-yellow.

Head inclined forward; spaces between ocelli and eyes depressed; frontoclypeus with the distal half laterally excavated and directed forward.

Pronotum with maximum height at middle; distal half of the median process and of lateroapical processes curved upward; apex of the lateroapical processes reaching the level of the $\mathbf{r}-\mathbf{m}$ crossvein of the tegmina.

The other features as in the genus description.

Genitalia. Aedeagus subcylindric in lateral view, more or less compressed antero-posteriorly and enlarged laterally in the distal half, more sclerotinized on dorsal surface, with a longitudinal protuberance in each side near the middle of the dorsal surface and with a minute prominent teeth in mosaic in the distal half of this surface, which appears also in a posterior view; functional orifice ovate and surrounded by a more os less membranous tissue. Paramere well developed, compressed laterally in it basal half, enlarged near middle and contorted to the apex, which is more sclerotinized, flattened laterally and pointed recurved upward and forward. Connective trapezoidal, sclerotinized. Lateral plate two times longer than large, with a conspicuous protuberance in the superior angle, which bears a more distinct 
pilosity than that present along the middle of the plate. Subgenital plate three times longer than in lateral view, compressed laterally and distinctly directed backward, viewed ventrally with a median notch more longer than half of the length of the -plate.

\section{Smilidarnis concolor sp. $\mathrm{n}$.}

(Figs. 9-13)

Type and type-locality. Holotype female with the following label data: “CORCOVADO [Rio de Janeiro-RJ] / GB - XI-1967/Alvarenga/Seabra leg" (manuscript). The type is deposited in the "Museu de Entomolia Pe. Jesus Santiago Moure", of the "Departamento de Zoologia da Universidade Federal do Paraná, Curitiba, Brasil".

Measurements (in mm). Head width: 3,12; head length: 1,24; distance between the humeral angles: 3,40 ; distance between the apices of the lateroapical processes: 1,38; pronotal length: 7,83; total length: 9,02.

Decription: Holotype female. General color gold-yellow; head little more clear in the spaces between coronal suture and eyes; pronotum with two longitudinal bands little more clear in direction of the muscular impressions of the metopidium and with a semilunar area at the sides of median third also little more clear; apex of the median process and of the lateroapical processes, black; tegmina and veins yellowish, with a darkening on first and second apical cells and also in a small portion of the first discoidal cell; ventral surface of the body and legs, yellowish.

Head inclined downward; spaces between ocelli and eyes plain; frontoclypeus with a callosity at the disc and with the distal half directed downward.

Pronotum with maximum height at the level of the space between humeral angles; apex of median process and of latero-apical processes slightly curved upward; apex of the latero-apical processes not reaching the level of the $\mathbf{r}-\mathbf{m}$ crossvein of the tegmina.

The other features as in the genus description, excepting for the pattern of $\mathbf{R}_{\mathbf{4}}$ and $\mathbf{R}_{\mathbf{5}}$ veins of the tegmina, which are distinctly divergent little before the external angle of the third apical cell.

Genitalia. Second valvulae blade-shaped, regularly arched from base to tip; dorsal margin with irregular and spaced protuberances on the pre-apical portion; apex rounded. Sternit VII more than two times larger than long in ventral view, broadly and deeply emarginated.

\section{DISCUSSION}

According to the key presented by DEITZ (1975) to subfamilies and tribes of Membracidae, this new genus goes to Cymbomorphini. A closed examination and comparison of the specimens of Smilidarnis gen. n. with Cymbomorpha Stal and Eumela Stal, show that they are not congeneric with none of them; Smiliodarnis gen. n. lacks the apposed processes on coxa and trochanter, dorsal pairs of fenestre 

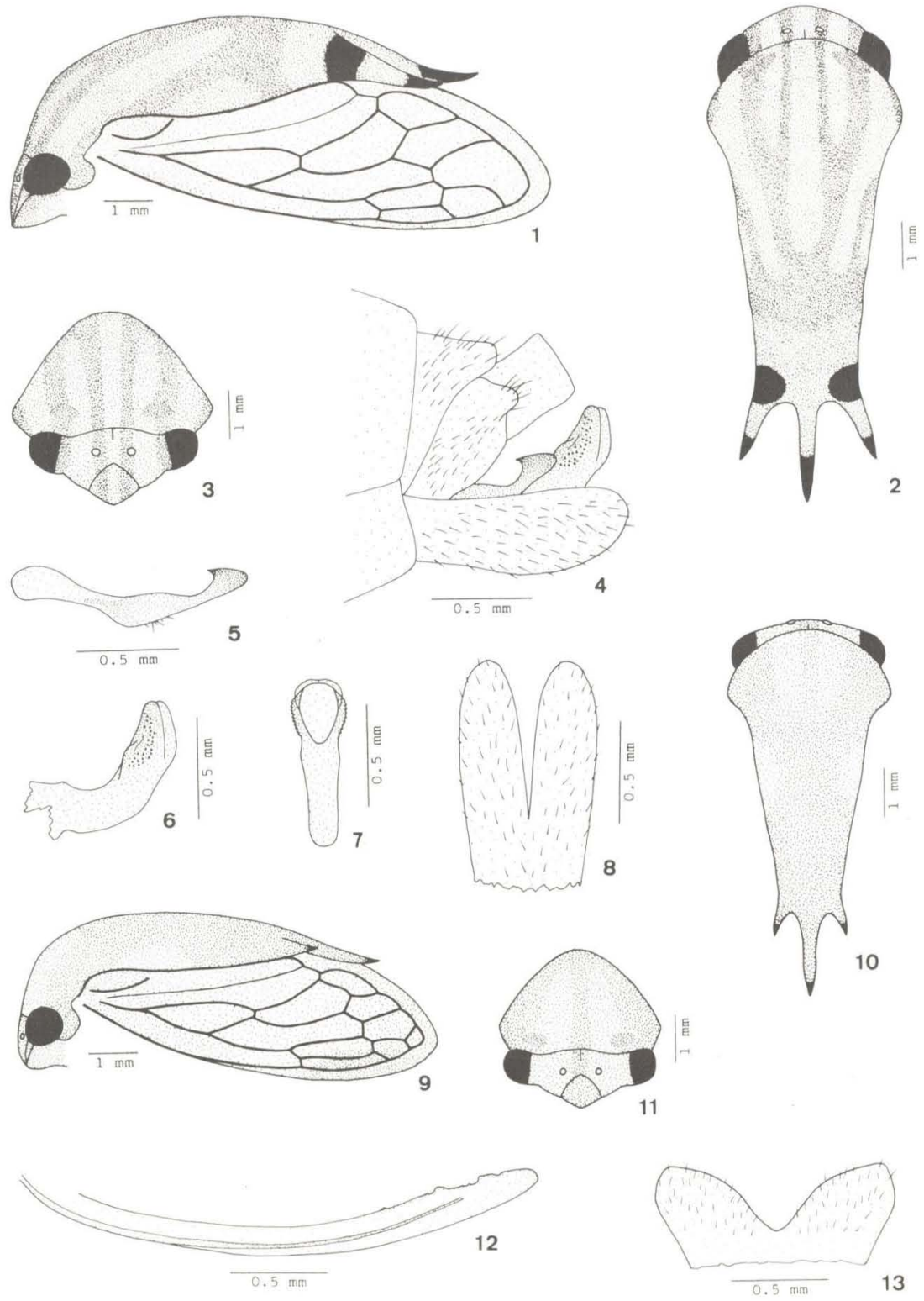

Figs. 1-8. Smilidarnis fasciatus sp. n. (holotype male). 1, head, pronotum and tegmina, lateral view; 2 , head and pronotum, dorsal view; 3 , head and pronotum, frontal view; 4 , genitalia, left lateral view; 5 , left paramer, left lateral view; 6 , aedeagus, left lateral view; 7 , aedeagus, posterior view; 8 , subgenital plate, ventral view.

Figs. 9-13. Smilidarnis concolor sp. n. (holotype female). 9, head, pronotum and tegmina, lateral view; 10, head and pronotum, dorsal view; 11 , head and pronotum, frontal view; 12 , second valvulae, left lateral view; 13 , sternite VII, ventral view. 
in abdominal segments III-VII, elevated middorsal tuberosities on abdomen and of a conspicuous dorsal carina, which are characters of one or both genus of Cymbomorphini.

Despite the presence of one $\mathbf{r}$, one $\mathbf{r}-\mathbf{m}$ and two $\mathbf{m}$-cu crossveins in the tegmina, and the presence of one $\mathbf{r}-\mathbf{m}$ crossvein in the hinwings, which are good characteristics for the greater number of Darninae, the strange fact is that the $\mathbf{R}$ and $\mathbf{M}$ veins of the tegmina are perfectly fused till the middle and divergent after; this pattern is exclusive of Ceresini and allied tribes of Smiliinae. The most recent studies in the general classification of new world Membracidae show that the venation pattern of the tegmina of Darninae is with $\mathbf{R}$ vein free and with $\mathbf{M}$ and $\mathbf{C u}$ fused basaly; none subfamily or tribe presents a combination of the tegmina and hindwings characters, as those found in Smilidarnis gen. n. .

We know that it is possible to occur aberrations in the wings venation, but it is difficult to believe that this aberration could appear on both tegmina and hindwings of two different species of the same genus, proceeding from a well distinct localities.

The male genitalia of $S$. fasciatus sp. $\mathrm{n}$. and the female genitalia of $S$. concolor sp. n., and also the chaetotaxy of the metathoracic legs of these species, show characters that are common to both Cymbomorphini and of Ceresini.

So, only with further studies will be possible to define where to place this new genus. More suitable is one of the DEITZ (op. cit.) considerations, when he treated about Cymbomorphini and Smiliinae: “. . . Genera in the Cymbomorphini and Hyphinoini of the Darninae resemble many of the Smiliinae in the chaetotaxy of the metathoracic tibia, shape of pronotum, and morphology of the male and female genitalia. Indeed, in some Cymbomorpha Stal $\mathbf{R}_{\mathbf{4}+5}$ and $\mathbf{M}_{\mathbf{1}+2}$ are confluent for a short distance (Fig. 19B) just as in the Smiliinae. These similarities suggest the Smiliinae may be derived from forms similar to members of the darnine tribes $\mathrm{Hy}-$ phinoini and Cymbomorphini. ...".

\section{AKNOWLEDGEMENT}

I wish to thank Dr. Albino Morimasa Sakakibara (Departamento de Zoologia da Universidade Federal do Paraná, Curitiba, Brazil), for the oportunity of studying the material and for his critical review of the manuscript.

\section{REFERENCES}

DEITZ, L.L., 1975. Classification of the higher categories of the new world treehoppers (Homoptera: Membracidae). N. C. Agric. Exp. Stn. Tech Bull., 225: 1-177. 